

Scand J Work Environ Health 1991;17(5):324-329

https://doi.org/10.5271/sjweh.1695

Issue date: Oct 1991

Gender-specific reproductive outcome and exposure to high-frequency electromagnetic radiation among physiotherapists.

by Larsen Al, Olsen J, Svane 0

Affiliation: Department of Occupational Medicine, Central Hospital, Esbjerg, Denmark.

This article in PubMed: www.ncbi.nlm.nih.gov/pubmed/1947918






\title{
Gender-specific reproductive outcome and exposure to high-frequency electromagnetic radiation among physiotherapists
}

\author{
by Anders I Larsen, MD, ${ }^{1}$ Jørn Olsen, $\mathrm{PhD},{ }^{2}$ Ole Svane, $\mathrm{MD}^{3}$
}

\begin{abstract}
LARSEN AI, OLSEN J, SVANE O. Gender-specific reproductive outcome and high-frequency electromagnetic radiation among physiotherapists. Scand J Work Environ Health 1991;17:324-9. The aim of this case-referent study was to investigate reproductive hazards other than congenital malformations after exposure to high-frequency electromagnetic radiation. Cases and referents were sampled from a cohort of pregnancies of members of the Union of Danish Physiotherapists through linkage of the union file with national medical registers. Case groups were spontaneous abortions and children with low birthweight, prematurity, and stillbirth/death within one year. Exposure to high-frequency electromagnetic radiation before and during pregnancy was assessed through telephone interviews. As referents to the 270 cases, 316 pregnancies were randomly sampled. A total of $8.4 \%$ did not participate. Only $23.5 \%$ of the children born by the highly exposed mothers were boys. This value is a statistically significantly altered gender ratio showing a dose-response pattern. High-frequency electromagnetic radiation was furthermore associated with low birthweight, but only for male newborns. The other outcomes were not statistically significantly associated with exposure to high-frequency electromagnetic radiation.
\end{abstract}

Key terms. birthweight, fecundity, gender ratio, perinatal mortality, prematurity, spontaneous abortion, case-referent study, epidemiology, shortwave diathermy.

High-frequency electromagnetic radiation is nonionizing radiation in the frequency range from $300 \mathrm{kHz}$ to $300 \mathrm{MHz}$ (corresponding to wavelengths between $1 \mathrm{~km}$ and $1 \mathrm{~m}$ in air). High-frequency electromagnetic radiation is widely used, for example, in health services (shortwave diathermy), industry (thermal plastic sealing and glue hardening), radar technology, and telecommunications. American exposure standards (1) are frequently exceeded in connection with health care and industrial use $(2,3)$.

Research into the interaction between high-frequency electromagnetic radiation and biological processes, including any influence on reproduction, is scarce, and most of the epidemiologic evidence may be biased due to insensitive exposure measures. Results have often been inconclusive or even conflicting.

Experimentally, exposure to relatively powerful electromagnetic fields results in the heating of biological materials, and powerful electromagnetic fields are able to induce many types of abnormal, reproductive end points (which may be thermal effects only) in animal experiments and in vitro. However, inference is more ambiguous when effects of lower levels of exposure are studied. Some animal studies suggest such athermal effects as reduced fertility (4), malformations

1 Department of Occupational Medicine, Central Hospital, Esbjerg, Denmark.

2 Institute of Social Medicine, University of Aarhus, Arhus, Denmark.

${ }^{3}$ National Labour Inspection, Copenhagen, Denmark.

Reprint requests to: Novo Nordisk, Occupational Health Service, Novo Allé, DK-2880 Bagsvaerd, Denmark.
$(5,6)$, reduced intrauterine growth $(5,7)$, embryo lethality (8), and changed postnatally detected behavior (9). However, local hyperthermia may have taken place incidentally in the exposed animals although a general rise in temperature could not be demonstrated in the study. Most western occupational exposure standards are based on the assumption that the risk associated with high-frequency electromagnetic radiation relates only to the thermal mechanism.

In Denmark, a small cluster of four newborns with malformations, born by physiotherapists exposed to high-frequency electromagnetic radiation during pregnancy $(10,11)$, initiated this study. Two of these children also had a low birthweight, one was stillborn, and one died perinatally.

The purpose of the study was to investigate the reproductive hazards of exposure to high-frequency electromagnetic radiation among female physiotherapists with special reference to effects on malformations, fertility, fetal development [growth, gender ratio (boys:girls), and intrauterine death], and perinatal mortality. The data on malformations have been published separately (11).

\section{Subjects and methods}

\section{Design}

The study was performed as a case-referent investigation within a cohort. The study base consisted of pregnancies conceived by members of the trade union (Union of Danish Physiotherapists) who delivered or miscarried between 1978 and 1985. Members of the 
study base were identified through linkage of the trade union file with the Danish register of births and medical registers of abortions. Women representing cases, and a sample of the study base, were interviewed by telephone by one of the authors (AIL) about exposure to high-frequency electromagnetic radiation during pregnancy and about confounding factors. At the time of the interview the interviewer did not know the outcome of the pregnancies.

\section{Subjects}

Physiotherapists were selected for the study since their exposure levels could be estimated with some certainty from interview data (12) and since they are hardly exposed to any other occupational physical or chemical agents that are toxic to the reproductive system.

Women born in 1933 or later and registered as members of the Union of Danish Physiotherapists in 1978 or later were included in the study. By using this sampling procedure, we identified almost all physiotherapists, as $98 \%$ of the physiotherapists in the country are registered in the union, employees as well as owners of private clinics. By means of the national civil registration number, the union file was linked to the Danish registers of births and in-patients, covering all births and all patients in Danish hospitals. Thus all spontaneous abortions treated at the hospitals and all deliveries in the period from 1978 to 1985 were recorded, and data on abortions (spontaneous and induced) and births (perinatal death, birthweight, gestation age at birth, gender) were obtained. Data about the mother's age and parity and the child's place of birth were also registered. The only outcome parameter provided from the interview was "time to pregnancy" (ie, the time from last use of contraception to the beginning of a recognized pregnancy) $(13,14)$. Twins and induced abortions were excluded from the study.

The following five partly overlapping case groups were defined: (i) spontaneous abortion (code 643 of the International Classification of Diseases: termination of pregnancy before 29th week), (ii) subfecundity (waiting time to pregnancy of more than six months), (iii) low birthweight ( $<2500 \mathrm{~g}$ ), (iv) prematurity (birth before 38th week of gestation), and (v) stillbirth or death in the first year of life.

The reference groups were a sample of all births for case group $\mathrm{i}$, and the same sample omitting actual cases for case groups ii-iv.

Fecundity was analyzed in the random sample of all pregnancies, and gender ratio (boys:girls) was determined for the sample of noncases.

The material is outlined in table 1 . Of the $4064 \mathrm{mem}-$ bers of the union in the period from 1978 to 1985,4021 could be completely identified, and $43(1 \%)$ could not.

Identified were 2334 pregnancies, including $29 \mathrm{ec}$ topic pregnancies and 542 induced abortions. A total of 270 cases was ascertained in the registers, and 316 pregnancies were sampled at random in the study base for the case-referent analysis. The case groups consisted of 166 spontaneous abortions $(7.1 \%$ of all pregnancies), 18 stillborn/deaths within one year (1.1\% of all births), 86 preterm births (5.4\%), and 44 low weight children $(2.5 \%)$. Of the sampled pregnancies 264 were noncases. The gender ratio for the total study base of births was a little higher than expected (52.6:47.4) compared with the national gender ratio (51.4:48.6).

Thirty-three women representing 41 pregnancies could not be reached by telephone. Two women (4 pregnancies) did not want to participate. Thus the total proportion of dropouts was $8.4 \%$. The nonrespondents were equally distributed among the cases and the noncases.

The four cases that generated the study were neither excluded from nor included in the study base.

\section{Exposure assessment}

Exposure assessment for the first month of pregnancy was based upon the following information: (i) main worktasks during the day [ie, manual physiotherapy, electrotherapy (ultrasound, short-wave diathermy), administrative work, and teaching] and (ii) characterization of the exposure to high-frequency electromagnetic radiation (ie, use of different types of electrodes, time spent in the short-wave room, frequency of shortwave use in the clinic, and direct versus indirect exposure). Indirect exposure was recorded if the woman worked within a distance of $1 \mathrm{~m}$ from a diathermy unit operated by a colleague. The following classification of the equipment corresponded to data on emission from the different types of electrodes (12): $0=$ circuplode or no exposure, 1 =diplode exposure, and $10=$ plate electrode exposure.

\section{Time-weighted exposure}

By multiplying three exposure factors [type of electrode, frequency of short-wave (high-frequency electromagnetic radiation) use in the clinic, and total time spent in the short-wave room], we constructed a time-

Table 1. Overall description of the study base of 2334 pregnancies among 4021 female physiotherapists.

Number Percent

Age at termination of pregnancy

$\begin{array}{lrr}\leq 24 \text { years } & - & 5.4 \\ 25-29 \text { years } & . & 44.1 \\ 30-34 \text { years } & . & 37.8 \\ \geq 35 \text { years } & & 12.7 \\ \text { Outcomes of the } 2334 \text { pregnancies } & & \\ \text { Ectopic pregnancies } & 29 & 1.2 \\ \text { Spontaneous abortions } & 166 & 7.1 \\ \text { Induced abortions } & 542 & 23.2 \\ \text { Twins } & 17 & 1.1 \\ \text { Other births } & 1580 & \\ \text { Gender distribution of all births } & & \end{array}$

Gender distribution of all births (boys : girls)

$52.6: 47.4$ 
weighted exposure index. This index was arbitrarily divided into three categories, of which the lowest level represented the absence of exposure or exposure to circuplodes only. The time-weighted exposure index was made a priori and independently of the data analysis.

Table 2. Gender distribution of the offspring of physiotherapists by different measures of high-frequency electromagnetic radiation - analyzed in a sample of noncases from the study base. (OR =odds ratio, $95 \% \mathrm{Cl}=95 \%$ confidence interval)

\begin{tabular}{|c|c|c|c|c|}
\hline & \multicolumn{2}{|c|}{$\begin{array}{l}\text { Gender of the } \\
\text { offspring }\end{array}$} & \multirow{2}{*}{ OR } & \multirow{2}{*}{$95 \% \mathrm{Cl}$} \\
\hline & $\begin{array}{l}\text { Male } \\
(\mathrm{N})\end{array}$ & $\underset{(\mathrm{N})}{\text { Female }}$ & & \\
\hline \multicolumn{5}{|l|}{$\begin{array}{l}\text { Time-weighted } \\
\text { exposure indexa, } b\end{array}$} \\
\hline $\begin{array}{l}0 \\
1 \\
2\end{array}$ & $\begin{array}{r}107 \\
11 \\
4\end{array}$ & $\begin{array}{l}71 \\
23 \\
13\end{array}$ & $\begin{array}{l}1.0 \\
3.2 \\
4.9\end{array}$ & $\begin{array}{l}- \\
1.5-7.1 \\
1.6-17.9\end{array}$ \\
\hline \multicolumn{5}{|l|}{ Type of electrodec } \\
\hline $\begin{array}{l}\text { None or circuplode } \\
\text { Diplode } \\
\text { Plate electrodes }\end{array}$ & $\begin{array}{r}99 \\
5 \\
18\end{array}$ & $\begin{array}{r}66 \\
7 \\
34\end{array}$ & $\begin{array}{l}1.0 \\
2.1 \\
2.8\end{array}$ & $\begin{array}{l}0.6-7.5 \\
1.5-5.5\end{array}$ \\
\hline \multicolumn{5}{|l|}{ Type of exposure } \\
\hline $\begin{array}{l}\text { None } \\
\text { Only direct } \\
\text { Only indirect } \\
\text { Both }\end{array}$ & $\begin{array}{r}99 \\
9 \\
6 \\
8\end{array}$ & $\begin{array}{l}65 \\
13 \\
11 \\
18\end{array}$ & $\begin{array}{l}1.0 \\
2.2 \\
2.8 \\
3.4\end{array}$ & $\begin{array}{l}0.9-5.6 \\
1.0-8.5 \\
1.4-8.7\end{array}$ \\
\hline \multicolumn{5}{|l|}{$\begin{array}{l}\text { Time per week spent } \\
\text { in shortwave rooma }\end{array}$} \\
\hline $\begin{array}{l}<1 \mathrm{~h} \\
1-10 \mathrm{~h} \\
11-20 \mathrm{~h} \\
>20 \mathrm{~h}\end{array}$ & $\begin{array}{r}101 \\
12 \\
6 \\
3\end{array}$ & $\begin{array}{l}67 \\
15 \\
11 \\
14\end{array}$ & $\begin{array}{l}1.0 \\
1.9 \\
2.8 \\
7.0\end{array}$ & $\begin{array}{l}0.8-4.4 \\
1.0-8.4 \\
2.1-31.3\end{array}$ \\
\hline
\end{tabular}

Table 3. Odds ratio for diagnosed spontaneous abortions according to exposure to high-frequency electromagnetic radiation. (OR = odds ratio, $95 \% \mathrm{Cl}=95 \%$ confidence interval)

\begin{tabular}{lcccc}
\hline $\begin{array}{l}\text { Time-weighted } \\
\text { exposure index } \mathrm{a}, \mathrm{b}\end{array}$ & $\begin{array}{c}\text { Referentsc } \\
(\mathrm{N})\end{array}$ & $\begin{array}{c}\text { Spontaneous } \\
\text { abortions } \\
(\mathrm{N})\end{array}$ & OR & $95 \% \mathrm{Cl}$ \\
\hline 0 & 202 & 111 & 1.0 & \\
1 & 37 & 20 & 1.0 & $0.5-1.8$ \\
2 & 20 & 15 & 1.4 & $0.7-2.8$ \\
\hline
\end{tabular}

a Test for trend $\mathbf{P}=0.484$.

b $0=$ no exposure, $1=$ low exposure, $2=$ high exposure.

- The reference group consisted of a sample of births from the study base.

Table 4. Subfecundity (waiting time to pregnancy of more than six months) according exposure to high-frequency electromagnetic radiation - analyzed in a sample of all pregnancies. (OR= odds ratio, $95 \% \mathrm{Cl}=95 \%$ confidence interval)

\begin{tabular}{lcccc}
\hline $\begin{array}{l}\text { Time-weighted } \\
\text { exposure index, }\end{array}$ & $\begin{array}{c}\text { Referents } \\
(\mathrm{N})\end{array}$ & $\begin{array}{c}\text { Subfecundity } \\
(\mathrm{N})\end{array}$ & OR & $95 \% \mathrm{Cl}$ \\
\hline 0 & 193 & 37 & 1.0 & \\
1 & 27 & 4 & 0.8 & $0.2-2.2$ \\
2 & 24 & 8 & 1.7 & $0.7-4.1$ \\
\hline
\end{tabular}

a Test for trend $P=0.330$.

b $0=$ no exposure, 1 = low exposure, $2=$ high exposure.

\section{Confounders}

Information on some of the potential confounders was gathered in the interview. The women were asked about their consumption of medicine, tobacco, and alcohol during pregnancy and about serious acute or chronic diseases during pregnancy. Information on other potential confounders - age, parity, year of pregnancy termination and child's place of birth were collected from the registers.

\section{Statistics}

Exact confidence limits (15) were used in the casereferent analysis comparing different levels of exposure. Mantel-Haenszel statistics (16) were used in the trend analysis, and logistic regression was employed in the modeling.

\section{Results}

Table 2 shows an unexpected low ratio of boys to girls for the physiotherapists exposed to high-frequency electromagnetic radiation, and a trend pattern supported the relationship. The association was also found for different components of exposure, such as type of electrode, time spent in the short-wave room, and relation to the short-wave equipment (own work with high-frequency electromagnetic radiation versus indirect exposure as a bystander) (table 2 ). However, the significant trend was mainly due to the difference between the exposed and unexposed persons. Among the exposed only, no statistically significant trend was observed (table 2) ( $P=0.75$, Fisher's exact test). None of the extraneous factors listed as potential confounders were determinants of the gender ratio.

Table 3 shows no significant association between exposure and recorded miscarriages. Allowing for extraneous risk factors of spontaneous abortion in the logistic regression analysis did not change the crude estimates given in the table in any important way. Controlling for smoking, alcohol consumption, and age in the optimum model produced an odds ratio of 1.4 [ $95 \%$ confidence interval $(95 \% \mathrm{CI}) 0.7-2.9$ ] for the highest exposure level (ie, the odds ratio did not deviate from the crude estimates given in table 3 ). It was not possible to control for earlier spontaneous abortions.

Furthermore, exposure to high-frequency electromagnetic radiation did not correspond to occurrence of delayed time to pregnancy (table 4). Only age was associated with this outcome, but after control for age, the odds ratio for high-frequency electromagnetic radiation remained exactly the same.

The occurrence of stillbirth or death within the first year of life was weakly and not statistically significantly associated with exposure to high-frequency electromagnetic radiation, as seen in table 5 . No excess risk was found for the boys. Control for potential confounders (age, parity, consumption of alcohol and tobacco) 
resulted in an adjusted odds ratio of 2.8 (95\% CI $0.7-11.5$ ) for the high exposure level; this value is similar to the crude estimate. The association between stillbirth or death and high-frequency electromagnetic radiation was weaker when the outcome was analyzed against the component of the time-weighted exposure index.

High-frequency electromagnetic radiation seemed to have a negative impact on length of gestation (not statistically significant however) and birthweight for male deliveries (tables 6 and 7). Use of tobacco and alcohol was significantly associated with these outcomes, as expected. However, when these factors were excluded from the logistic regression models, the models kept their ability to explain variation, and the risk estimates for high-frequency electromagnetic radiation remained the same.

Ultrasound exposure during pregnancy, analyzed as a simple dichotomous parameter (work with ultrasound, yes/no), did not correlate with any of the outcome parameters when controlled for high-frequency electromagnetic radiation exposure. Consequently, ultrasound exposure was not a confounder.

\section{Discussion}

The deficit of newborn boys among the exposed physiotherapists was an unexpected, but rather striking, finding, one furthermore supported by the consistent association with different indicators of exposure and by simple dose-response patterns. It is not quite unreasonable that bystander exposure could imply a higher risk than direct exposure (table 2), since the duration of bystander exposure often exceeds that of the operator herself. The operator remains close to the equipment only a few minutes per treatment session, while the colleague in the section next to the equipment may be exposed continuously at a significant level as long as the equipment is switched on.

Table 5. Stillbirth or death within one year by mother's exposure to high-frequency electromagnetic radiation. (OR = odds ratio, $95 \% \mathrm{Cl}=95 \%$ confidence interval)

\begin{tabular}{|c|c|c|c|c|}
\hline $\begin{array}{l}\text { Time-weighted } \\
\text { exposure index }{ }^{a, b}\end{array}$ & $\begin{array}{l}\text { Referents } \\
\text { (N) }\end{array}$ & $\begin{array}{l}\text { Stillbirths } \\
\text { or deaths } \\
\text { within one } \\
\text { year } \\
\text { (N) }\end{array}$ & OR & $95 \% \mathrm{Cl}$ \\
\hline $\begin{array}{l}0 \\
1 \\
2\end{array}$ & $\begin{array}{r}201 \\
37 \\
19\end{array}$ & $\begin{array}{r}11 \\
3 \\
3\end{array}$ & $\begin{array}{l}1.0 \\
1.5 \\
2.9\end{array}$ & $\begin{array}{l}0.3-5.3 \\
0.6-10.7\end{array}$ \\
\hline
\end{tabular}

Table 6. Prematuritya of the boys and girls according to mother's exposure to high-frequency electromagnetic radiation. (OR= odds ratio, $95 \% \mathrm{Cl}=95 \%$ confidence interval)

\begin{tabular}{|c|c|c|c|c|c|c|c|c|}
\hline \multirow[b]{2}{*}{$\begin{array}{l}\text { Time-weighted } \\
\text { exposure index }\end{array}$} & \multicolumn{4}{|c|}{ Boys $^{d}$} & \multicolumn{4}{|c|}{ Girlse } \\
\hline & $\begin{array}{l}\text { Referents }{ }^{\mathrm{c}} \\
\text { (N) }\end{array}$ & $\begin{array}{l}\text { Preterm } \\
\text { births } \\
\text { (N) }\end{array}$ & OR & $95 \% \mathrm{Cl}$ & $\begin{array}{l}\text { Referents } \\
\text { (N) }\end{array}$ & $\begin{array}{l}\text { Preterm } \\
\text { births } \\
\text { (N) }\end{array}$ & OR & $95 \% \mathrm{Cl}$ \\
\hline $\begin{array}{l}0 \\
1 \\
2\end{array}$ & $\begin{array}{r}115 \\
11 \\
5\end{array}$ & $\begin{array}{r}29 \\
4 \\
4\end{array}$ & $\begin{array}{l}1.0 \\
1.4 \\
3.2\end{array}$ & $\begin{array}{l}0.4-4.7 \\
0.7-13.2\end{array}$ & $\begin{array}{l}74 \\
24 \\
13\end{array}$ & $\begin{array}{r}31 \\
9 \\
5\end{array}$ & $\begin{array}{l}1.0 \\
0.9 \\
0.9\end{array}$ & $\begin{array}{c}. \\
0.4-2.1 \\
0.3-2.8\end{array}$ \\
\hline
\end{tabular}

a Prematurity $=$ gestation period of less than 38 weeks.

b $0=$ no exposure, $1=$ low exposure, 2 = high exposure.

c The reference group consisted of a sample of births from the study base not containing the actual case group.

dest for trend $\mathrm{P}=0.087$.

e Test for trend $P=0.817$.

Table 7. Low birthweight ${ }^{a}$ of the boys and girls according to mother's exposure to high-frequency electromagnetic radiation (OR $=$ odds ratio, $95 \% \mathrm{Cl}=95 \%$ confidence interval)

\begin{tabular}{|c|c|c|c|c|c|c|c|c|}
\hline \multirow[b]{2}{*}{$\begin{array}{l}\text { Time-weighted } \\
\text { exposure index }\end{array}$} & \multicolumn{4}{|c|}{ Boys $^{d}$} & \multicolumn{4}{|c|}{ Girls $^{e}$} \\
\hline & $\begin{array}{l}\text { Referentsc } \\
\text { (N) }\end{array}$ & $\begin{array}{l}\text { Low } \\
\text { birth- } \\
\text { weights } \\
\text { (N) }\end{array}$ & OR & $95 \% \mathrm{Cl}$ & $\begin{array}{l}\text { Referents } \\
(\mathbf{N})\end{array}$ & $\begin{array}{l}\text { Low } \\
\text { birth- } \\
\text { weights } \\
\text { (N) }\end{array}$ & OR & $95 \% \mathrm{Cl}$ \\
\hline $\begin{array}{l}0 \\
1 \\
2\end{array}$ & $\begin{array}{r}118 \\
12 \\
5\end{array}$ & $\frac{12}{3}$ & $\begin{array}{l}1.0 \\
0.0 \\
5.9\end{array}$ & $\begin{array}{c}. \\
1.0-28.2\end{array}$ & $\begin{array}{l}75 \\
24 \\
13\end{array}$ & $\begin{array}{r}16 \\
6 \\
2\end{array}$ & $\begin{array}{l}1.0 \\
1.2 \\
0.7\end{array}$ & $\begin{array}{c}0.4-3.3 \\
0.0-3.2\end{array}$ \\
\hline
\end{tabular}

a Low birthweight $=$ birthweight less than $2500 \mathrm{~g}$.

b $0=$ no exposure, $1=$ low exposure, 2 = high exposure.

c The reference group consisted of a sample of births from the study base not containing the actual case group.

d Tesit for trend $P=0.087$.

e Test for trend $P=0.846$. 
The possibility that high-frequency electromagnetic radiation has a detrimental effect on male fetuses is raised in this study as a hypothesis which requires further investigation. It is also likely that the association was exaggerated to some extent due to the a posteriori finding and the excess number of males both in the sample of unexposed persons and in the study base. The explanation for the difference in gender ratio between the study base (52.6:47.4) and the background population (51.4:48.6) is unknown, and knowledge of the gender ratio for children of different professional groups has not been established. However, as the 1597 births constitute $100 \%$ of all births by $98 \%$ of the Danish physiotherapists, selection bias cannot explain this deviance. Compared with the gender ratio of the background population (51.4:48.6), the gender ratio of the highest exposed group (3:14) (table 2) still deviated statistically significantly $(P=0.02$, chi-square test).

On the other hand the association could also be biased towards null values due to the unavoidable risk of misclassifying the exposure according to the relevant exposure time period. If the effect of the exposure on the gender ratio is only of importance in a certain, short time window of the pregnancy or the time before pregnancy, then an exposure assessment based upon the first month as such might be rather imprecise.

Only simple tests for trend were performed. Although some of the exposure scales are probably nonlinear, knowledge of the nature of the biological effect of high-frequency electromagnetic radiation is sparse and did not permit the construction of models other than arbitrary ones. Therefore, the tests for trend only tested a linear component of the dose-response relationship, and it was not reasonable to fit a slope.

Data were collected on mother's parity, age, and consumption of alcohol and tobacco, but none of these factors confounded the study. Likewise it seems unlikely that information bias could explain the main findings. The effect of high-frequency electromagnetic radiation on the children's gender ratio was shown for noncases only to avoid biased recall from mothers to cases. And recall bias based upon the mother's knowledge of the gender of the children is unlikely, as the association between high-frequency electromagnetic radiation and gender was unexpected. Furthermore, the completeness of the material and verification of the expected dependence of birthweight and length of gestation on tobacco and alcohol consumption support the validity of the results.

The average number of pregnancies per woman in the case-referent study was as low as 1.2; thus bias in terms of lack of independence concerning multiple pregnancies in the study is not likely to have occurred (17). Furthermore, restricting the study to only one pregnancy per woman did not change the findings (data not shown).

Information bias might have been responsible for the apparent association between high-frequency elec- tromagnetic radiation and stillbirth or death within the first year of life. However, information bias did not manifest itself in the group of spontaneous abortions. Furthermore, the gender-specific influence on gestation length and birthweight speaks against a general risk of information bias.

Although the data did not reveal an association between high-frequency electromagnetic radiation and spontaneous abortion, an excess risk of early, nonclinical abortions among exposed fetuses (especially males) could not be ruled out in this study.

Likewise, lack of an observed association between "time to pregnancy" and exposure does not exclude the possibility that mainly female embryos are conceived in cases of exposure before or around conception. Time to pregnancy grouped into broad categories is hardly a measure sensitive enough to demonstrate an effect of this kind if only infertility is expressed, as long as the egg is presented to an androspermatozoon.

The results are based on sparse data and must be interpreted with caution. Several questions remain unanswered, and therefore a need for both experimental and epidemiologic research in the future is indicated.

Determination of the gender of abortions could indicate whether male embryos are aborted more than expected or whether high-frequency electromagnetic radiation affects eggs or spermatozoa. Some results indicate the possibility of clastogenic properties of electromagnetic radiation, perhaps even at nonthermal exposure levels (18).

The occurrence of low birthweight and prematurity could point to a less specific mode of action, perhaps affecting mainly male fetuses. It is well documented that the gender ratio during embryogenesis, and perhaps also later, gradually decreases and that extraneous factors can intensify this process $(19,20)$. However, no gender-specific risk of stillbirths and early childhood death was seen in this study. The fact that gender did not modify the occurrence of stillbirth and death within the first year of life - as opposed to the effect on prematurity - could indicate that male fetuses with severe damage do not survive till birth if exposed.

No abnormal gender ratio has been reported from animal experiments, but the occurrence of the other end points is consistent with findings from these studies $(5,7)$.

The knowledge of interaction between electromagnetic radiation - for example, in the shortwave region (high-frequency electromagnetic radiation) - and biological tissue is sparse, primarily due to lack of epidemiologic studies with a detailed exposure classification. The findings of this study were unexpected and are put forward as a new hypothesis which needs further elaboration. This study points at high-frequency electromagnetic radiation as a potential cause of reproductive damage. 


\section{Acknowledgments}

The study received financial support from Arbejdsmiljøfondet (grant 1986-21).

\section{References}

1. American National Standards Institute (ANSI). American national standard safety level with respect to human exposure to radio frequency electromagnetic fields, 300 $\mathrm{kHz}$ to $100 \mathrm{GHz}$. New York, NY: ANSI, 1982. (ANSI C95.1-1982.)

2. Suess MJ, ed. Nonionizing radiation protection. Copenhagen: World Health Organization, 1980. (WHO European series; no 10 ).

3. Skotte J. Reduction of radiofrequency exposure to the operator during short-wave diathermy treatments. J Med Eng Technol 1986;10:7-10.

4. Brown-Woodman PDC, Hadley JA, Richardson L, Bright D, Porter D. Evaluation of reproductive function of female rats exposed to radiofrequency fields $(27.12 \mathrm{MHz})$ near a shortwave diathermy device. Health Phys 1989;56:521-5.

5. Berman E, Kinn JB, Carter B. Observations of mouse fetuses after irradiation with $2.45 \mathrm{GHz}$ microwaves. Health Phys 1978;35:791-801.

6. Tofani S, Agnesod G, Ossola P, Ferrini S, Bussi R. Effects of continuous low-level exposure to radiofrequency radiation on intrauterine development in rats. Health Phys 1986;51:489-99.

7. Jensh RP. Studies of the teratogenic potential of exposure of rats to $6000-\mathrm{MHz}$ microwave radiation: I. morphologic analysis at term. Radiat Res 1984;97:272-81.

8. Brown-Woodman PDC, Hadley JA. Studies of the teratogenic potential of exposure of rats to $27.12 \mathrm{MHz}$ pulsed shortwave radiation. J Bioelectricity 1988;7: 57-67.

9. Jensh RP. Studies of the teratogenic potential of ex- posure of rats to $6000-\mathrm{MHz}$ microwave radiation: II postnatal psychophysiologic evaluations. Radiat Res 1984;97:282-301.

10. Larsen AI, Jensen AO, Skotte J, Istre O. Kan ikkeioniserende stråling have indvirkning på fosterudviklingen? [Does non-ionizing radiation influence foetal development?]. Ugeskr Laeger 1987;149:518-20.

11. Larsen AI. Congenital malformations and exposure to high-frequency electromagnetic radiation among Danish physiotherapists. Scand J Work Environ Health 1991;17:318-23.

12. Larsen AI, Skotte J. Can exposure to electromagnetic radiation (in diathermy operators) be estimated from interview data? - a pilot study. Am J Ind Med 1991; 19:51-7.

13. Baird DD, Wilcox AJ, Weinberg CR. Use of time to pregnancy to study environmental exposures. Am J Epidemiol 1986;124:470-80.

14. Rachootin $\mathbf{P}$, Olsen $\mathbf{J}$. The risk of infertility and delayed conception associated with exposure in the Danish workplace. J Occup Med 1983;25:394- 402 .

15. Rothman KJ. Modern epidemiology. Boston, MA: Little, Brown and Company, 1986.

16. Mantel N. Chi-square tests with one degree of freedom: extension of the Mantel-Haenszel procedure. J Am Stat Assoc 1963;58;690-700.

17. Butler WJ, Kalasinski LA. Statistical analysis of epidemiologic data of pregnancy outcomes. Environ Health Perspect 1989;79:223-7.

18. Yao KTS. Cytogenetic consequences of microwave irradiation on mammalian cells incubated in vitro. J Hered 1982;73:133-8.

19. Kellokumpu-Lehtinen P, Pelliniemi LJ. Sex ratio of human conceptuses. Obstet Gynecol 1984;64:220-2

20. Jakobovits AA, Jakobovits A, Iffy L. Sex ratio of fetuses during the second trimester of gestation. Acta Anat 1986;126:54-6.

Received for publication: 18 December 1990 